\title{
Resquícios antropofágicos na arte contemporânea brasileira
}

O modernismo brasileiro que se instaura a partir da Semana de Arte Moderna em 1922 é um tópico cultural com relação ao passado colonial e ao futuro da globalização. Neste contexto ainda prolifera um modelo de irreverência que sustenta um regime ético e estético como modo estratégico de inserção cultural dentro e fora do país.

A constituição formativa do nosso modernismo, além de resgatar um vínculo com o passado colonial e buscar uma forma vanguardista, ao formular um projeto de construção de identidade brasileira, cria a problemática da Antropofagia cultural basear-se-ia no conceito oriundo das idéias manifestadas pelo poeta e ensaísta Oswald de Andrade, desenvolvidas nas décadas de 20 e 30 . Tal conceito auxilia no entendimento de um momento cultural onde os artistas e intelectuais brasileiros estão focados em dois problemas: por um lado, uma apreensão das formas de ruptura com a tradição acadêmica proveniente das vanguardas européias instauradas em nosso meio no início do século XX, com o propósito radical de repensar o problema da representação e do caráter ilusionístico das artes plásticas; e por outro, a antropofagia cultural volta-se para uma apreensão da cultura popular do nosso próprio país utilizando-a como temática, fato que se encontra estritamente relacionado ao projeto estético ao modo brasileiro. Juntamente com esse novo pensamento artístico, vem a notória vontade e afirmação dos modernistas, de certo caráter pedagógico, correlativo com a intenção de difundir idéias relacionadas a construção de uma identidade nacional para o público espectador. Assim, os modernistas adotam meios de disseminação dos seus conceitos, publicando manifestos e textos, como modo de entendimento direto a quem os assistia ${ }^{1}$.

\footnotetext{
Nunca fomos catequizados. Fizemos foi Carnaval. O índio vestido de senador do Império. Fingindo de Pitt. Ou figurando nas óperas de Alencar cheio de bons sentimentos portugueses. [...] Já tínhamos o comunismo. Já tínhamos a língua surrealista. A idade de ouro. [...] Contra as sublimações antagônicas. Trazidas nas caravelas. [...] Mas não foram cruzados que vieram. Foram fugitivos de uma civilização que estamos comendo, porque somos fortes e vingativos como o Jabuti. (Trecho do Manifesto Antropófago de Oswald de Andrade)
}

A busca pela nacionalidade e por um caráter único de assimilação e repulsa que gostariam de promover os modernistas, com relação ao que era produzido na Europa, tem suas concepções

\footnotetext{
${ }^{1}$ Modo também de assimilação dos modelos culturais da Europa nesse momento histórico, pois a publicação de manifestos e textos foi à maneira encontrada pelas vanguardas estrangeiras para a disseminação de seus ideais. CF: SCHWARTZ, Jorge:Vanguardas Latino-americanas. Textos críticos e manifestos. SP: Fapesp/Edusp, 1995.
} 
criadas a partir do entendimento de escritos épicos como o do viajante alemão Hans Staden. Ele vem ao Brasil no século XVI e é capturado pela tribo indígena dos Tupinambá, com sorte, consegue voltar à terra natal e escreve um livro dedicado ao príncipe H. Philisen, contando sua trajetória no país ermo e como quase fez parte de um ritual antropofágico²:

\footnotetext{
Quando eu ia indo pelo mato, ouvi dos dois lados do caminho uma grande gritaria, como costumam fazer os selvagens, e avançando para o meu lado. Reconheci então que me tinham cercado [...] Eu orava e esperava o golpe; porém, o rei, que me queria possuir, disse que desejava levar-me vivo para casa, para que as mulheres me vissem e se divertissem à minha custa, depois do que matar-me-ia e Kawewi pepicke*, isto é, queriam fabricar a sua bebida, reunir-se para uma festa e me devorar conjuntamente. (STADEN, 1557, pp.68 - 70)
}

Sabe-se que esse ritual faz parte da idéia de apropriação do outro; um "comer" o inimigo para dele abastecer-se, um assimilar o outro para dele aproveitar o que há de bom. Nesse sentido, os modernistas foram vorazes em suas traduções da cultura primitiva e popular brasileira e citam em seus manifestos vanguardistas a força dessa assimilação do que vem de "fora", no sentido de absorvê-la e recriá-la, não na acepção de "engoli-la" e reproduzi-la. Era essa a idéia que os modernistas gostariam de embutir no país, essa "nova" maneira do fazer artístico; a concepção de conhecer e recriar, que gostariam que se mantivesse nas obras produzidas por quem representava a cena brasileira em arte, literatura, música, etc.

Mais contemporaneamente, essa busca da criação de uma identidade para esse lugar que se reinventa, a pesquisa e o ensaísmo de cunho ao mesmo tempo ficcional e poético encontra aporte; O Brasil não é longe daqui, de Flora Sussekind, traça entre devaneios literários e relatos de viagem uma composição figurada para esse país descrito exótico e ainda paisagístico. ${ }^{3}$

A obsessão pela origem o que traz consigo?* Possíveis romances familiares. Alguns imensos, em vários tomos. Árvores, genealogias insaciáveis, com raízes firmes e em contínua, vertiginosa, multiplicação de ramos exemplares. Alguns menores possíveis de cortes abruptos, fins de linha ou linhas duplas. [...] Também possíveis histórias de desenvolvimento individual, romance de aprendizado. Ainda aí, imagem vegetal semente, fruto - enlaçada à árvore familiar, ao reiterado jogo de espelhos entre

\footnotetext{
${ }^{2}$ STADEN, Hans. . Primeiros registros escritos e ilustrados sobre o Brasil e seus habitantes. SP: Terceiro Nome, 1999.

${ }^{3}$ SUSSEKIND, Flora. O Brasil não é longe daqui. O narrador, a viagem.SP: Companhia das Letras, 2000.
} 
biografia e biologia, à mão única socialmente prefigurada para o aprendizado, o amadurecimento. (SUSSEKIND, 1955, p.11)

Já Sérgio Buarque de Holanda, intelectual contemporâneo de Oswald e de Mário de Andrade, e autor do clássico de interpretação nacional, Raízes do Brasil ${ }^{4}$, relata social e historiograficamente nossa constituição cultural através da descrição de imagens. Preocupado em analisar nossa herança colonial, compreendeu a formação da cultura nacional por meio de sentimentos e relações pessoais que destacavam o homem brasileiro aos olhos dos outros povos. As diversas reflexões sobre a identidade nacional manifestadas na sua obra classificam o texto como instrumento para a compreensão da nossa realidade e vem confirmar certo compromisso da intelectualidade brasileira de traçar uma interpretação geral do país. O maior interesse do autor consiste na idéia de definir o Brasil, o brasileiro e a identidade nacional ao examinar possibilidades, direções e limites dessa civilização e baseado em sua estranheza, conforme escreve já no parágrafo de abertura de Raízes, “[...] somos ainda uns desterrados em nossa terra”.

Silviano Santiago, em As raízes e o labirinto da América Latina (2006), se debruça sobre os escritos de Sérgio Buarque de Holanda e do mexicano Octávio Paz, para reabrir o debate sobre o tema da identidade latino-americana. $\mathrm{O}$ autor levanta reflexões críticas detalhadas, a esse universo de nossas raízes e o labirinto intrínseco em que se encaixa a América Latina num tempo globalizado. Porém toda essa narrativa de Santiago é atravessada por outro texto produzido pelo próprio em 1978: "O entre-lugar do discurso latino-americano", que se encontra no livro Por uma literatura nos trópicos. $\mathrm{O}$ autor ressalta que está no entre-lugar quem se nega a adotar o discurso e a identidade do outro como seu, ao mesmo tempo em que a assimila gerando uma tensão paradoxal:

\footnotetext{
Entre o sacrifício e o jogo, entre a prisão e a transgressão, entre a submissão ao código e a agressão, entre a obediência e a rebelião, entre a assimilação e a expressão, ali nesse lugar aparentemente vazio, seu templo e seu lugar de clandestinidade, ali se realiza o ritual antropófago da literatura latino-americana.
} (SANTIAGO, 1978, p.28)

Talvez se possa dizer que os modernistas se encaixaram, ainda que avant la létre ao conceito entre-lugar, criado muitas décadas após suas vertiginosas experiências estéticas e intelectuais. Por um lado não gostariam de ser aquelas mesmas coisas que já foram “os estrangeiros” e por outro,

${ }^{4}$ BUARQUE de HOLLANDA, Sérgio. Raízes do Brasil. São Paulo, Companhia das Letras, 1995. 
sabem que precisam buscar nas raízes as concepções revisionistas do movimento, e ao mesmo tempo manter uma consonância estrita com os novos modelos estéticos da Europa.

Importantes movimentos vanguardistas posteriores ao da Semana, também trariam a idéia lançada pelos modernistas de renovar o pensamento artístico. O Concretismo nos anos 50, o Neoconcretismo na década de 60 , e seus desdobramentos nos anos conseguintes ${ }^{5}$ consolidaram um modo inovador de fazer arte no país, um modo que não se encontrava em catálogos estrangeiros. Porém, como na ruptura dos anos 20 , eles traziam à tona a premissa de uma criação elucidativa, explicativa, já que a invenção da obra caminharia a par a da invenção do espectador-leitor. Isto gera uma interrogação presente aos educadores, produtores e artistas contemporâneos: refletindo a possibilidade em nosso país de ainda hoje desvincular o objeto artístico ou a teoria da arte, da produção simultânea de espectadores e leitores numa nação que é reinventora intrínseca de sua própria história e que se re-significa constantemente..

Todavia, as complexidades do mundo contemporâneo com as quais os artistas e intelectuais brasileiros se deparam no presente, demonstram outros aspectos outros aspectos e referências que não são tão visíveis numa primeira abordagem como era o caso da tensão dialética entre o local e o exterior, no caso dos modernistas. Entre estas novas complexidades que a história das últimas décadas apresenta, faz com que uma consciência mais acurada do lugar da enunciação discursiva e cultural no mundo e, sobretudo, a quem essas enunciações se dirigem. Ou seja, quem fala, de onde,e para quem. Hoje, toda uma geração de artistas e escritores é ciente das políticas globalizadas de inserção estética, que diferem das de seus predecessores históricos, no sentido de que o mundo globalizado demanda distintas atitudes de cunho ético e político, em face das velozes mudanças sociais deste período.

A marca mais visível de mudança que se colocaria crescentemente, nas operações de alguns artistas brasileiros de sensibilidade oriunda dos neo-concretos, é a difícil passagem das formulações do período da ditadura militar para um sistema periférico, no qual o neoliberalismo encontra-se em constante expansão. Por esse motivo, havíamos convocado, já nas primeiras linhas deste trabalho, o conceito de Entre-lugar como uma

\footnotetext{
${ }^{5}$ Dois movimentos de concepção altamente nacionais: pelo novo código construtivo dos artistas de São Paulo e principalmente pela vertente do Rio de Janeiro com Hélio Oiticica, Lygia Clark, Lygia Pape e outros, onde se criou uma nova concepção de arte. "O neoconcretismo estabeleceu a crise da representação no plano bidimensional e um novo estatuto da obra de arte. [...] mas foi no texto 'teorias do não-objeto', de Ferreira Gullar, [...] que um olhar mais amplo sobre as pesquisas poéticas dos artistas neoconcretos e um anuncio da questão do objeto forma vitais para se entender os anos 60 na arte brasileira e suas relações com a sociedade. [...] O objeto trazia, implicitamente, uma nova posição do espectador no acionamento de seus significados e a "participação do espectador na obra de arte' [...]" In: REIS, Paulo R. O. Arte de Vanguarda no Brasil: os anos 60. RJ. Jorge Zahar Ed. 2006.
} 
ferramenta teórica que nos auxiliasse a contextualizar as instâncias nas quais o trabalho estético brasileiro contemporâneo opera ainda hoje, ao formular novamente a tensão das passagens de elementos nacionais num circuito artístico internacional.

Embora o conceito criado por Silviano Santiago, na década de 70, tenha sido formulado para dar conta de sutis manobras sobre a inserção da literatura latino-americana no Primeiro Mundo, o momento atual de neoliberalismo e globalização, em grande medida, recoloca esta problemática, também no campo da arte.

De um ponto de vista mais intrínseco sobre a gramática da arte contemporânea brasileira, alguns artistas consagrados tais como Tunga, Waltércio Caldas ou Cildo Meirelles, optam claramente por um remanejamento de nossa tradição modernista. Assim, uma das saídas do construtivismo e em certa medida também do neoconcretismo, representado mais claramente nas obras de Lygia Clark e Hélio Oiticica, operada por esses artistas, passa por uma espécie de revisionismo e de uma reincorporação de alguns dados do surrealismo, por um lado, e da antropofagia, por outro. Ou seja, para sair da tradição concreta, onde os possíveis dados narrativos e alegóricos são de certo modo foram interditados,já que o construtivismo tende a compreender a forma em si como tema narrativo, é como se os artistas pós neo concretos voltassem atrás na linha do tempo, recuperando uma certa condição fabular surrealista, que já se apresentava na obra dos modernistas antropofágicos, como forma de possibilitar um retorno da narrativa ao campo da nossa arte.

Há, com efeito, no ideário de artistas como Cildo, Tunga ou Waltércio, uma concepção da arte muito próxima daquela que havia sido formulada por Georges Bataille, que atribui a grandiosidade da condição estética, à medida em que ela se efetiva no campo do jogo, do dispêndio e do sagrado, e na vizinhança do erotismo e da morte. ${ }^{6}$ Esta analogia com Bataille é possível, na medida em que parte das obras oriundas da vertente neoconcreta são submetidas à uma condição sagrada e profundamente ritualística na maneira como persegue uma crescente trata a proliferação de sentidos com as quais persegue a constituição mais primordial de seu processo.

\footnotetext{
${ }^{6}$ CF: BATAILLE, Georges. Lascaux o el nascimiento del arte.Tradução, apresentação e notas de Axel Gasquet. Córdoba Argentina: Alción, 2003.

.El erotismo. Tradução ao espanhol de Maria Luiza Bastos. Buenos Aires: Sur, 1960.

..Teoria da Religião.Tradução de Sérgio Góes de Paula e Viviane de Lamare. SP: Ática,

1993.
}

História do Olho.Tradução de Eliane Robert de Moraes. SP: Cosac\&Naify, 2003. 
A aproximação existente entre parte do modernismo brasileiro, e em ampla medida, de algumas tendências vanguardistas em outros países da América Latina, cujo interesse em comum, reside na busca por forças inconscientes ou primitivas, gerou o estabelecimento de um diálogo destas tendências locais, com o surrealismo europeu. Mas, as influências recíprocras que daí advém, ainda permanecem em nosso país, sem serem estudadas em profundidade. ${ }^{7}$ Esta é então, uma obscura confluência cultural, que parte da desbordante obra de nossos artistas e que contém ecos de proximidade com o surrealismo - entre as décadas de 20 até pelo menos, os anos 60 - que não foi não de todo reconhecida, ou pelo menos, devidamente avaliada.

Em certa medida, o trabalho de artistas como Tunga ou Cildo digere parte de elementos formais, de temas e conceitos de obras que foram produzidas na confluência entre a revalorização de temáticas locais populares e barrocas, que se mesclaram com alguns dos propósitos surrealistas, conforme mencionamos anteriormente.

Dentro do modernismo brasileiro anterior ao predomínio dos projetos formais de ordem construtiva, percebe-se que o surrealismo europeu partilha com nosso barroco em face moderna, de uma mesma tendência a um transbordamento das formas. Mas indo um pouco além neste raciocínio que marca a analogia mais evidente entre estes dois dispositivos da arte, se poderia dizer também, que tal como o barroco histórico europeu, o surrealismo tem uma capacidade de se apropriar das novas formas de seu tempo, utilizando-se de certa retórica popular, através da tentativa de entrar na cultura de massas, ao mesmo tempo em que incorpora alguns elementos desta mesma cultura. E tal como o barroco diante das regradas premissas expressivas do classicismo, o surrealismo seria criticado negativamente por outro aspecto que têm em comum: o fato de cometerem, segundo as palavras do arquiteto Adolf Loos, o "crime do ornamento". 8

\footnotetext{
${ }^{7}$ Cf. a opinião do professor Robert Ponge, responsável pelo volume coletivo Surrealismo e Novo Mundo (Porto Alegre, Ed. Da UFRGS, 1999), em uma entrevista, é a de que a história do surrealismo no Brasil ainda está para ser escrita, e que até alguns anos atrás, a hipótese dominante era a de não houve surrealismo no Brasil antes dos anos 60, mas que também quase não se procurava entender e explicar o que poderia ter motivado essa ausência. Ponge reconhece que as coisas estão mudando, e já se pode contar com alguns trabalhos instigantes sobre o assunto. $\mathrm{O}$ autor pauta ainda que embora a chegada do surrealismo na América tenha sido extremamente rápida, através de experiências com a escrita automática feitas por Prudente de Morais Neto, e Sérgio Buarque de Holanda, ainda nos anos 20; e na Argentina por um grupo de estudantes em torno de Aldo Pellegrini, a recepção do movimento variou muito entre grupos e pessoas. E que, específicamente entre nós, apesar da simpatia de alguns pequenos casos isolados, o clima dominante tendeu a ser reticente. Ponge atribui à esta situação cultural de hostilidade ao surrealismo, ao conservadorismo cultural e ideológico, e a um retorno à ordem, como conseqüências diretas das políticas de severas limitações nos sucessivos governos de Vargas a partir dos anos 30. PONGE, Robert. O Surrealismo na América Hispânica e no Brasil. Entrevista a Luciana Hidalgo.In: Agulha. Revista de Cultura. N. 18/19, Fortaleza/São Paulo, nov.dez de 2001.

${ }^{8} \mathrm{O}$ pensador alemão Theodor Adorno, em ensaio tardio sobre o surrealismo, menciona a expressão de Loos, um membro do movimento "Nova Objetividade", e que, segundo Adorno, "sofreu o choque
} 
A incorporação de um procedimento simulado no próprio modo como os materiais se apresentam no objeto de arte, bem como um profundo entendimento da artificialidade da linguagem- dispositivo barroco por excelência- irão colocar o surrealismo, como a contra-face daquela outra tendência conceitual da vanguarda histórica de vertente formal como os movimentos alinhados dentro da esfera do construtivismo ou concretismo, e cujas premissas políticas e estéticas haviam sido focadas num elegante rigor formal baseado na autonomia dos meios expressivos.

Alguns artistas que se detiveram nas novas resoluções formais operadas pelas vanguardas européias, justamente através do surrealismo, com um interesse temático que parece ser menos interessado na marca expressiva da sensibilidade artística individual, e mais focado na de ordem coletiva das culturas primitivas, iriam elaborar um vínculo ideológico bem aliançado com o dos surrealistas franceses. Uma artista como Tarsila do Amaral, nas bem conhecidas pinturas do auge do projeto antropofágico, ou mais tardiamente, a escultora Maria Martins, cuja obra, admirada por Breton ${ }^{9}$, é ao mesmo tempo, emblemática tanto de sua condição de artista e de pessoa cosmopolita, são ambas, exemplos desta peculiar confluência, que mescla a novidade formal européia e culta, com a rememoração mítica e idealizada do elemento bárbaro, através da presença das lendas indígenas locais.

Algumas das operações que Maria Martins elabora em suas esculturas a partir da década de 40, já constituem um descolamento do primeiro modelo antropofágico oswaldiano. Apesar de manterem um elo temático vindicativo de alguns valores exóticos das culturas amazônicas, há em suas esculturas de títulos sugestivos, uma discursividade que já não se encontra na descoberta da alteridade dos elementos locais e estrangeiros em primeira mão, mas que é pautada numa espécie de exacerbação das tensões antropofágicas da geração anterior, concernentes a uma dialética do interno-externo, o que equivale a dizer, que nos encontramos em um contexto da arte onde as delimitações

surrealista", no sentido de que o surrealismo relembraria o incômodo da incapacidade de lidar com o fato de que "a sua racionalidade permanece irracional." Adorno argumenta que o surrealismo é justamente, o complemento de tendências racionalistas da arte do mesmo período. Cf. ADORNO, Theodor. Revendo o Surrealismo.In: Notas de Literatura I. Trad. e apresentação de Jorge de Almeida. SP: 34, Duas Cidades, col. Espírito Crítico, 2003.pp135/140. .

${ }^{9}$ André Breton foi autor de um texto de apresentação para uma exposição de Maria Martins na galeria Julien Lèvy em Nova York, no ano de 1947, onde o encantamento europeu diante das culturas exóticas se encontra manifestado no trecho que reproduzimos a seguir: "Não era nada menos que o Amazonas, que cantava nas suas obras, que tive a felicidade de tanto admirar, em Nova York, em 1943. Cantava com todas as suas vozes imemoriais a paixão do homem, do nascimento até a morte, tal como souberam condensá-la em símbolos mais envolventes que todos os outros. (...) Maria soube captar como ninguém, na fonte primitiva, de onde ela emana, asas e flores, sem nada dever à escultura do passado ou do presente." Citado por CANTON, Kátia. In: Maria Martins: a mulher perdeu sua sombra.In: XXIV Bienal de São Paulo. Núcleo Histórico. Catálogo. SP: Fundação Bienal, 1998. 
entre a forma e o conteúdo, ainda são, em certa medida, identificáveis. Mas há uma espécie de diferimento pioneiro por parte de Maria Martins em relação ao primeiro modernismo, justamente através de uma tensão dúplice do elemento interno, que parece ser entendido pela artista, ao mesmo tempo, tanto como uma poderosa energia do inconsciente de um sujeito individual (aliás bastante afirmado), quanto como a energia da alma coletiva do mito do selvagem.

Estes elementos que constituem o aspecto interno de sua obra iriam, extensivamente, afetar diretamente o lado externo, ou o próprio modo como sua escultura se apresenta no mundo. Sua escultura é então, de uma revelação formalmente nada pacífica, mas extremamente conflitiva frente a algumas posições teóricas sobre a obra de arte moderna, durante o período do entre-guerras. Algumas destas argumentações, entre elas a do crítico americano Clement Greenberg, fazem por sim mesmas, parte de um amplo corpo teórico que não será analisado ao longo deste texto, mas que postos aqui brevemente, demonstram uma reação um tanto incômoda, no sentido de que a exuberância barroca e tropical de sua obra, iria parecer contextualmente inadequada, afrontando, portanto, aquela espécie de pudor estético gerado pelas difíceis situações do período da guerra. ${ }^{10}$

Mas, por outro lado, Maria Martins, através da marca singular de sua arte, iria também alimentar o imaginário europeu de sua necessidade reprimida durante o contexto da guerra, de uma fabulação em torno da exuberância e da sensualidade

\footnotetext{
${ }^{10}$ Tais reações críticas de natureza negativa sobre a obra da escultora, são analisadas por Raúl Antelo, tanto em relação ao contexto norte-americano, quanto brasileiro, da qual destacamos aqui, a menção à uma resenha crítica feita por Clement Greenberg para The Nation, datada de maio de 1944, onde a exposição de Maria Martins na galeria Valentine é mencionada. Para Antelo, a opção antiformalista de Maria pode ser dimensionada através da leitura notavelmente formalista do crítico americano, que considera entre outras coisas, "que a natureza do metal quase nega a si mesma na monstruosa e feliz proliferação de formas animais e vegetais"; sublinhando ainda que, "o impulso é barroco e não moderno e é dado pela decoração latina e pela luxúria tropical". (Tradução minha; citado no texto de Antelo no original em inglês). No contexto do Brasil, Antelo menciona uma reflexão feita por Mário Pedrosa, onde o crítico lê um "romantismo" na escultura de Maria, que seria tributário de uma concepção literária, justamente pautada no surrealismo, e posta sob o lema de Breton: "La beauté sera convulsive, ou ne será pás". Pedrosa vai além, advertindo sobre os perigos extravagantes dos procedimentos artísticos de Maria pois, "o fundo de seu impulso criador não é plástico, mas discursivo. Revela-se nessas obras, com despudor sublime e demasiada satisfação a personalidade da escultora. Há nisso tudo, é verdade, certo fundo inconsciente de exibicionismo, fruto de insuperado infantilismo psíquico ou de uma ingenuidade total, que desarma porque não se guarda, não se poupa ou não se inibe. E neste defeito ou nesta qualidade, como queiram, está o segredo da explicação artística de Maria.” Antelo observa que, embora Maria tenha sido vista como uma praticante ingênua do realismo mágico, era também, por outro lado, sensível aos problemas da redefinição nominalista da arte, e nesse sentido, o ensaísta trata de perceber as influências conceituais recíprocas entre a escultora e Duchamp. Cf. ANTELO, Raúl. Maria com Marcel. In: Discutir el cânon. Tradiciones y valores en crisis. Buenos Aires: C.A.I.A. (Centro de Investigadores argentinos de arte), 2003. pp11/27.
} 
primitivas $^{11}$, antecipando uma série de alusões temáticas sobre o assunto que, feitas posteriormente por artistas como Tunga dilatar este espaço imaginativo, além de colocar a questão dos mecanismos de produção e recepção da arte brasileira no circuito do exterior, pois Tunga, tal como Maria, vai constituindo o corpo de sua obra a partir de um movimento nômade, de cidadão do mundo, que retro-alimenta um teor de nacionalismo ficcional.

Uma parte da fabulação exótica, certa brasilidade encenada, é comum ao repertório artístico tanto de Maria quanto de Tunga, além da matriz surrealizante partilhada pelos dois artistas, principalmente em relação aos aspectos largamente emocionais e intuitivos de suas obras. Isto gera uma somatória que vai desde os conflitos verdadeiros do Brasil, até a idéia de um país primitivo e imaginário, espécie de depositório da natureza selvagem e tropical, enquanto valor simbólico e nostálgico de desejo do Outro.A adição de ficções e alegorias visitam então, a temática antropofágica.

Nesse sentido vale a pena chamar a atenção para a "brasilidade" um tanto selvagem com a qual Tunga faz questão de marcar seu território no circuito globalizado da arte, provocando, ainda, efeitos de alteridade radical que são muito próximos daqueles sofridos pelos primeiros europeus que pisaram no país. Esta alteridade que se encontra no presente, através da obra do artista, potencializa os efeitos de estranhamento de nosso passado colonial, ao remanejamento das premissas antropofágicas de nosso modernismo e o problema da constituição da identidade nacional, "no país da cobra grande" ${ }^{12}$, que passa no presente, pelo entendimento de que ela se constitui através de uma marca plural, heterogênea e descontínua. ${ }^{13}$

\footnotetext{
${ }^{11}$ A diferença cultural de Maria Martins em relação a seus colegas europeus e norte-americanos, deve-se em grande parte, aos títulos sublinhados em primeira pessoa, como em Não te esqueças nunca que eu venho dos trópicos; ou ainda em títulos que se beneficiam dos ícones de nossa tradição popular narrativa e religiosa como Yemanjá ou Yara, entre tantos outros.

${ }^{12}$ Jorge Schwartz nos relembra em nota, que "Cobra Grande" é o espírito das águas da mitologia indígena da Amazônia, que foi, inclusive objeto do poema antropofágico Cobra Norato de Raul Bopp, também de 1928. Cf. Vanguardas latino-americanas, manifestos e textos críticos. SP: Edusp/Fapesp, 1995.. p.

142. Raúl Antelo adiciona, que o poema de Bopp dedicado a Tarsila do Amaral, foi ilustrado, em sua edição de 1931, por Flávio de Carvalho, na de 1937, por Goeldi, e na de 1954, por Joan Miró. E ainda, que o mesmo motivo amazônico percorre a rapsódia de Mário de Andrade em Macunaíma, quando ao final da narrativa, o herói não consegue resistir à sedução da mãe das águas, caindo na armadilha de Vei, a sol, que havia mandado a Iara, para seduzí-lo. Segundo Antelo, Maria Martins alude aos mitos amazônicos em simetria ao que Geraldo Ferraz, na necrológica da artista, havia pautado sobre as esculturas do final dos anos 30, onde estes motivos selváticos remissivos do "mundo perdido",se configuram energicamente. Obras que, como sua escultura, não por acaso, intitulada de Cobra Grande, postulariam uma retomada radical de temas esboçados anteriormente na pintura de Tarsila. Cf. ANTELO, Raúl. Op. Cit, p. 15. 


\section{Referências Bibliográficas:}

ADORNO, Theodor. "Revendo o Surrealismo". In: Notas de Literatura I. Trad. e apresentação de Jorge de Almeida. SP: 34, Duas Cidades, col. Espírito Crítico, 2003.

ANDRADE, Oswald. Manifesto Antropófago. In: Revista de Antropofagia, Ano 1, № 1, maio de 1928.

ANTELO, Raúl. "Maria com Marcel”. In: Discutir el cânon. Tradiciones y valores en crisis. Buenos Aires: C.A.I.A. (Centro de Investigadores argentinos de arte) , 2003.

BATAILLE, Georges. Lascaux o el nascimiento del arte. Tradução, apresentação e notas de Axel Gasquet. Córdoba Argentina: Alción, 2003.

El erotismo. Tradução ao espanhol de Maria Luiza Bastos. Buenos Aires:

Sur, 1960.

Lamare. SP: Ática, 1993

Teoria da Religião. Tradução de Sérgio Góes de Paula e Viviane de

História do Olho. Tradução de Eliane Robert de Moraes. SP:

Cosac\&Naify, 2003.

BRETON, André, citado em: CANTON, Kátia. In: "Maria Martins: a mulher perdeu sua sombra”.In: XXIV Bienal de São Paulo. Núcleo Histórico. Catálogo. SP: Fundação Bienal, 1998.

HOLANDA, Sérgio Buarque de. (1936). Raízes do Brasil. SP. Companhia das Letras. 2006.

PONGE, Robert. “O Surrealismo na América Hispânica e no Brasil”. Entrevista a Luciana Hidalgo.In: Agulha. Revista de Cultura. N. 18/19, Fortaleza/São Paulo, nov.dez de 2001.

REIS, Paulo R. O. Arte de Vanguarda no Brasil: nos anos 60. RJ. Jorge Zahar Ed. 2006. SANTIAGO, Silviano. As raízes e o labirinto da América Latina. RJ. Rocco. 2006

Debates. 1978.

Uma literatura nos trópicos - Ensaios sobre dependência cultural. SP:

STADEN, Hans (1557). . Primeiros registros escritos e ilustrados sobre o Brasil e seus habitantes. SP: Terceiro Nome, 1999.

SUSSEKIND, Flora (1955). O Brasil não é longe daqui. SP. Cia. das Letras. 1990

SCHWARTZ, Jorge. Vanguardas latino-americanas. Polêmicas, manifestos e textos críticos. SP: Iluminuras, Edusp, Fapesp, 1995. 